\title{
Inter-specific hybridization underlies phenotypic variability in Daphnia populations
}

\author{
Hans Georg Wolf and Mona A. Mort * \\ Max-Planck-Institut für Limnologie, Abteilung Ökophysiologie, Postfach 165, D-2320 Plön, Federal Republic of Germany
}

Summary. In the glacial lakes of the Palaearctic three species of Cladocera commonly coexist: Daphnia hyalina, $D$. galeata, and D. cucullata. Frequently these populations contain not only animals which are morphologically typical for the species but also individuals of an intermediate phenotype. Electrophoretic investigations of allozyme-patterns in morphologically typical individuals reveal that each species is fixed for a different allele at the GOT locus. Morphologically intermediate animals are heterozygous for the alleles of the two species which they resemble. The allelic pattern at other loci is also consistent with the assumption that morphological intermediates are formed via interspecific hybridization. Very few backcrosses between galeatahyalina hybrids and their parent species are found, and there is no indication of gene flow between D. cucullata and the other species.

Inter-specific hybridization, while common among plants, is rare in the animal kingdom (Mayr 1963). Individuals intermediate in phenotype between two sympatric species are commonly attributed to inter-specific hybridization (Mayr 1963; Ford 1975). Such phenotypic intermediates present taxonomic difficulties which obscure phylogenetic and ecological relationships. Populations of the small (1-3 mm) crustacean cladoceran Daphnia often contain individuals intermediate in phenotype between the typical forms of coexisting species (Brooks 1957a, b; Einsle 1966, 1983; Flößner 1972; Hebert 1978; Lieder 1983), at times resembling hybrid swarms in which most individuals are phenotypic intermediates (Brooks 1957a). In addition, sympatric populations of different species tend to resemble each other more than allopatric populations of one species (Brooks 1957b). Although several authors have suggested a link between the observed patterns of phenotypic variability and inter-specific hybridization (Brooks $1957 \mathrm{~b}$; Flößner 1972; Lieder 1983; Hebert 1984), this hypothesis has been tested with genetic evidence only for two pond-dwelling Australian species, D. carinata and D. cephalata (Hebert 1985), but no genetic information is available for large-lake species.

Offprint requests to: H.G. Wolf

* Present address: Division of Biological Sciences, University of Michigan, Ann Arbor, MI 48109, USA
Three Daphnia species commonly coexist in the glacial lakes of the Palaearctic: D. hyalina Leydig, D. galeata Sars and D. cucullata Sars. Taxonomic works place D. hyalina and D. galeata in close phylogenetic relationship, with $D$. cucullata somewhat more distantly related to these species. Hybridization between $D$. galeata and $D$. hyalina has long been suspected (Einsle 1966, 1983; Flößner 1972), and Lieder (1983) interprets a series of morphologically intermediate individuals as arising via interspecific hybridization between $D$. galeata and $D$. cucullata. In a study of 16 lakes in northern FRG and 2 lakes in southern FRG, we identified typical forms of these three species, and also individuals which express intermediate phenotypes (Fig. 1). Using allozyme electrophoresis, we determined the genetic composition of typical as well as intermediate forms to test the hypothesis of interspecific hybridization with genetic evidence.

\section{Material and methods}

\section{Sampling}

Animals were collected by oblique tows with a $250 \mu \mathrm{m}$ mesh plankton net from 16 lakes in northern FRG (within a $30 \mathrm{~km}$ radius of Plön, Holstein) and 2 lakes in southern FRG [Bodensee (Lake Constance) and Schluchsee (Black Forest)]. Care was taken to sample animals from all depths in order to get a random sample and avoid possible complications due to different vertical migration patterns of different types. The animais were transported alive to the laboratory and scored for phenotype. Then these animals were placed individually in $20 \mu \mathrm{l}$ of the appropriate electrophoresis buffer and frozen at $-18^{\circ} \mathrm{C}$. Electrophoresis was carried out within two weeks after collection.

\section{Electrophoresis}

Vertical discontinuous polyacrylamide gels were used for the determination of glutamate-oxaloacetate-dehydrogenase (GOT) genotypes. The concentration gel consisted of $3 \%$ acrylamide in $0.05 \mathrm{M}$ Tris-phosphoric acid buffer (pH 6.7), the separation gel of $7.7 \%$ acrylamide in $0.38 \mathrm{M}$ Tris- $\mathrm{HCl}+20 \%$ sucrose ( $\mathrm{pH} 8.9$ ). The upper electrode buffer consisted of $0.04 \mathrm{M}$ Tris-glycine $(\mathrm{pH} 8.9)$, the lower electrode buffer of $0.12 \mathrm{M}$ Tris- $\mathrm{HCl}(\mathrm{pH} 8.08$ ). Individual Daphnia were homogenized in $20 \mu \mathrm{l}$ of concentration-gel buffer $+10 \%$ sucrose + bromphenol blue and loaded onto the gel. Separation was carried out at $6 \mathrm{~W}$ until the brom- 
phenol blue migrated into the separation gel and then continued at $12 \mathrm{~W}$ for a total separation time of $3.5 \mathrm{~h}$. Gels were then removed from the apparatus and stained in the dark for $1 \mathrm{~h}$ in: $3.56 \mathrm{~g} \mathrm{Na}_{2} \mathrm{HPO}_{4}, 265 \mathrm{mg}$ aspartic acid, $74 \mathrm{mg} \alpha$-ketoglutarate, $100 \mathrm{mg}$ EDTA, $20 \mathrm{mg}$ pyridoxal phosphate, $500 \mathrm{mg}$ polyvinylpyrrolidone, and $250 \mathrm{mg}$ Fast Blue $\mathrm{BB}$, per $100 \mathrm{ml}$ water.

Horizontal starch gel electrophoresis was used for the determination of allelic patterns at phosphoglucose isomerase (PGI), phosphoglucomutase (PGM), malate dehydrogenase (MDH), aldehyde oxidase (AO), and partly for GOT. Electrophoretic procedures and staining recipes for PGI, PGM, MDH, and AO are those given in Mort and Wolf (1985) and are similar to those given in Wolf (1982).

\section{Results}

\section{Distribution of phenotypes}

In most of the 16 lakes studied we found typical forms as well as morphological intermediates, which exhibit characteristics of two of the typical forms. Figure 1 shows the general shape of the head of each form plus the insertion site of the first antennae, which is the most useful single character for distinguishing between the different forms (Flößner 1972, Hrbáček unpublished). In a given lake, both typical and intermediate forms can be collected simultaneously, confirming their sympatric distribution.

\section{Enzyme patterns}

Genotypes are represented by symbols indicating relative migration rates of gene products as follows: $\mathrm{s}^{-}$, slowest, $\mathrm{s}$, slow, $\mathrm{m}$, medium, $\mathrm{f}$, fast, $\mathrm{f}^{+}$, very fast, and $\mathrm{f}^{++}$, fastest. At GOT, six banding patterns were found: 3 single-banded patterns, ss, ff, and $\mathrm{s}^{-} \mathrm{s}^{-}$, interpreted to represent homozygotes, and 3 triple-banded patterns, $\mathrm{sf}^{-} \mathrm{s}^{-} \mathrm{f}, \mathrm{s}^{-} \mathrm{s}$, interpreted to represent heterozygotes (GOT is a dimeric enzyme). At PGI, ten banding patterns were found, four single-banded patterns (homozygotes) and six triple-banded patterns (heterozygotes). The alleles were designated $\mathrm{s}^{-}, \mathrm{s}, \mathrm{m}$, and $\mathrm{f}$, respectively. At PGM 15 banding patterns with five alleles $\left(\mathrm{s}, \mathrm{m}, \mathrm{f}, \mathrm{f}^{+}\right.$, and $\left.\mathrm{f}^{++}\right)$were found, five single banded homozygotes and ten double-banded heterozygotes (PGM is a monomeric enzyme). At MDH six different banding patterns with 3 alleles $\left(\mathrm{s}, \mathrm{f}\right.$, and $\mathrm{f}^{+}$) were found, three singlebanded homozygotes and three triple-banded heterozygotes. At $\mathrm{AO}$ three banding patterns with 2 alleles (s and f) were found, two single-banded homozygotes and one triple banded heterozygote. Thus, at all loci, all possible combinations of alleles were observed. The genetic basis of the enzyme phenotypes is inferred from previous studies (Hebert and Ward 1972) and from the stability of patterns in laboratory clones.

\section{Associations between morphology and allozymes}

When individuals are scored for phenotype (Fig. 1) and then identified for genotype at the GOT locus, there is a clear relationship between phenotype and genotype (Table 1). The typical forms of the three species are each homozygous for a different allele $(D$. galeata for $f, D$. hyalina for $\mathrm{s}$, and $D$. cucullata for $\mathrm{s}^{-}$); the intermediate forms are heterozygous for alleles carried by the species which they resemble.

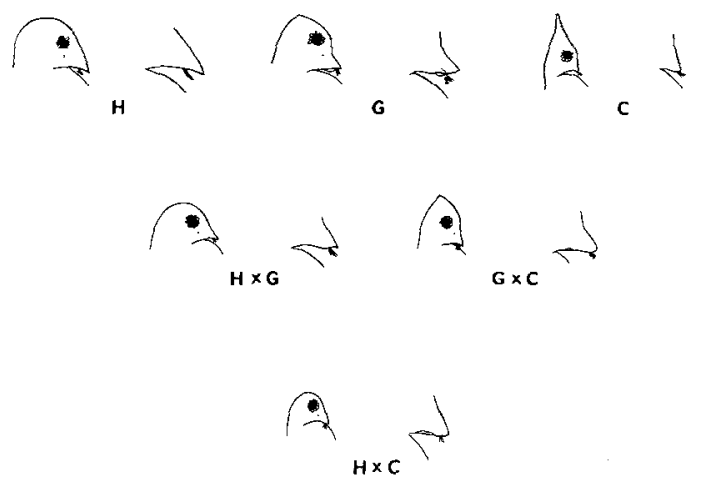

Fig. 1. Typical phenotypes of Daphnia species and intermediate forms used for electrophoretic comparisons: $H D$. hyalina, $G D$. galeata, and $C$ D. cucullata. Camera lucida drawings were made of specimens collected in 2 lakes as follows: $H, G$, and $H \times G$, Schöhsee, 10 September 1984; $C, G \times C$, and $H \times C$, Plußsee, 11. September 1984. The drawings show the head shape and location of the insertion of the first antenna (slightly enlarged). The scale bar represents $1 \mathrm{~mm}$ for the complete head drawings

The distribution of alleles at loci other than GOT supports a model of separate gene pools for the typical phenotypes (Table 2). For example, at PGI the $\mathrm{s}^{-}$and $\mathrm{s}$ alleles are found only in D. cucullata, at PGM the $\mathrm{f}^{++}$allele is found only in $D$. hyalina. At AO the s-allele is typical for $D$. hyalina, whereas the $\mathrm{f}$-allele is found in D. galeata and D. cucullata. On the other hand, some alleles are never found in typical animals of a given species, e.g. at $\mathrm{MDH}$ the s-allele is never found in D. hyalina, and in D. galeata the $\mathrm{f}^{+}$-allele is never found.

The morphologically intermediate animals exhibit the expected allelic combinations not only at the GOT locus, but at all other loci; thus intermediates between $D$. hyalina and $D$. galeata are not only heterozygous sf at GOT but also heterozygous sf at AO. Whenever in a given animal an allele is encountered which is found in only one typical form but not in other morphologically typical forms, this animal also carries the GOT-allele of this typical form. Thus, PGI $s$ and $\mathrm{s}^{-}$are always accompanied by GOT s ${ }^{-}$.

Given the relationship between GOT genotype and Daphnia phenotype, the proportions of a Daphnia assemblage belonging to parental and hybrid classes can be electrophoretically determined. The GOT genotype distributions show that, at a given time of the year, lakes differ with respect to frequencies of parental and hybrid classes (Table 3). During late summer, certain lakes lack hybrids (e.g. Tresdorfer See) while others (e.g. Höftsee) appear to be dominated by hybrids or contain hybrids for which one of the parental classes is rare or missing (e.g. Großer Plöner See).

Comparison of the genotypes represented in Tables 1 and 3 illustrates seasonal, within-lake shifts in composition of the Daphnia assemblages. For example, in a late-April sample from the Schöhsee (Table 1), D. cucullata was wellrepresented, but was absent in a mid-August sample (Table 3). Similarly, hyalina-galeata hybrids were not found in a May sample from the Belauer See (Table 1) but were common in a mid-August sample (Table 3). In most lakes, the parental species associated with given hybrid classes have been found at some point during the growing season. Seasonal succession of species has been previously docu- 
Table 1. Relationship between Daphnia phenotype and genotype at the GOT locus

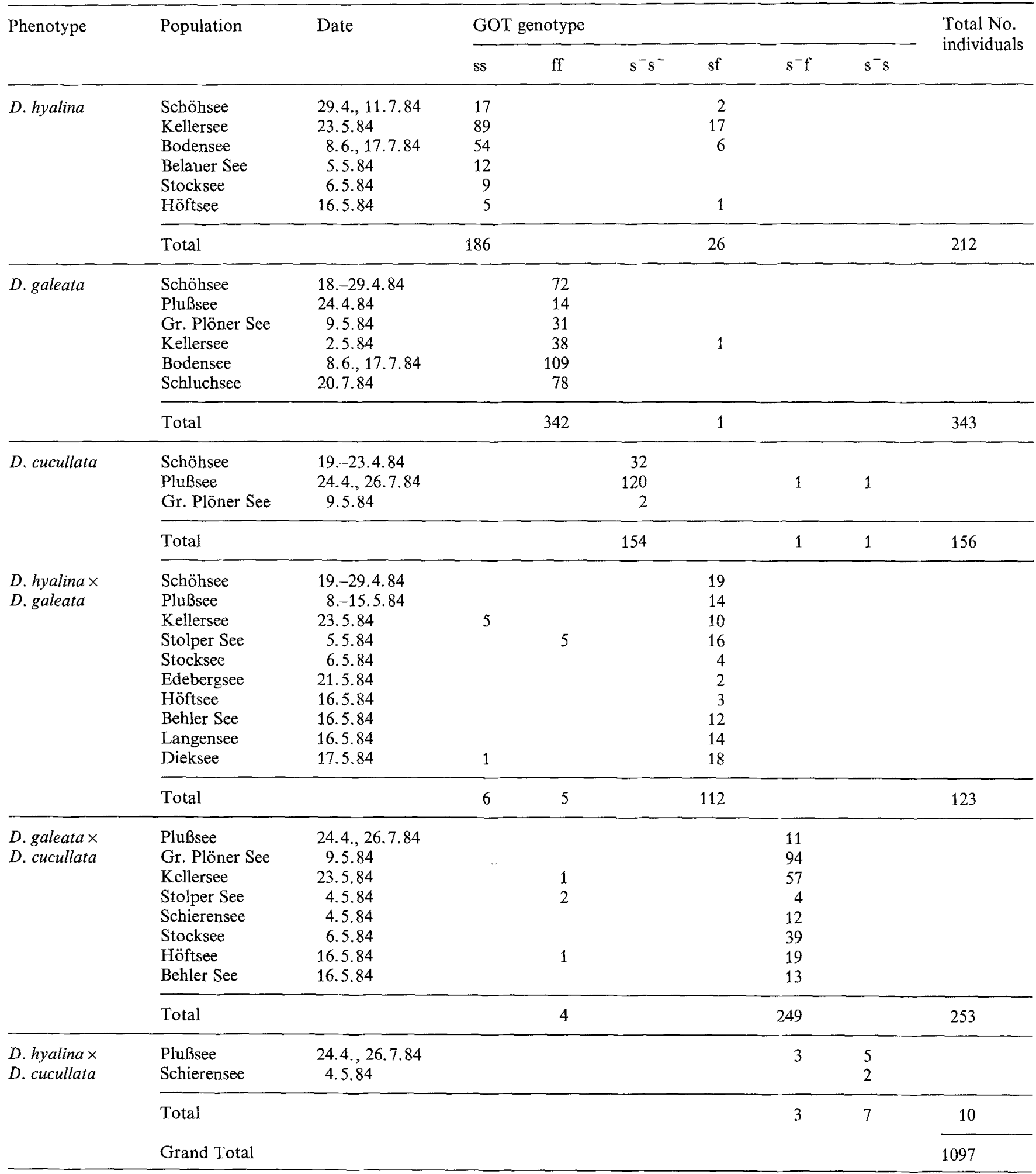

mented; the present study provides evidence for seasonal succession of parent species and hybrids.

\section{Discussion}

The observed genotypic pattern, especially the clear association of specific GOT genotypes with all six phenotypes, suggests the formation of intermediate phenotypes via interspecific hybridization. Successfull laboratory mating has been observed between $D$. hyalina and D. galeata; the descendants of such crosses show the expected enzyme patterns, confirming the possibility of hybridization between these species. Until now it was not possible to induce mating in D. cucullata in the laboratory. 
Table 2. Alleles found for 3 Daphnia species at 5 polymorphic enzyme loci: GOT, PGI, PGM, MDH, and AO

\begin{tabular}{|c|c|c|c|c|c|c|}
\hline \multirow[t]{2}{*}{ Locus } & \multicolumn{2}{|c|}{ D. hyalina } & \multicolumn{2}{|c|}{ D. galeata } & \multicolumn{2}{|c|}{ D. cucullata } \\
\hline & $\mathrm{N}$ & Alleles & $\mathrm{N}$ & Alleles & $\mathrm{N}$ & Alleles \\
\hline GOT & 2,381 & $\mathrm{~s}$ & 13,222 & $f$ & 1,896 & $s^{-}$ \\
\hline PGI & 2,632 & $\mathrm{~m}$ & 26,835 & $\mathrm{~m}, \mathrm{f}$ & 4,651 & $\mathrm{~s}^{-}, \mathrm{s}, \mathrm{m}, \mathrm{f}$ \\
\hline PGM & 2,507 & $\mathrm{~m}, \mathrm{f}, \mathrm{f}^{+}, \mathrm{f}^{++}$ & 26,079 & $\mathrm{~s}, \mathrm{~m}, \mathrm{f}, \mathrm{f}^{+}$ & 4,447 & $\mathrm{~s}, \mathrm{~m}$ \\
\hline $\mathrm{MDH}$ & 2,144 & $\mathrm{f}, \mathrm{f}^{+}$ & 14,276 & $\mathrm{~s}, \mathrm{f}$ & 2,411 & $s, f, f^{+}$ \\
\hline $\mathrm{AO}$ & 847 & $s$ & 4,112 & $\mathrm{f}$ & 296 & f \\
\hline $\begin{array}{l}\text { No. of } \\
\text { lakes }\end{array}$ & & 13 & & 18 & & 6 \\
\hline
\end{tabular}

The exceptions to the pattern (Table 1) can be attributed to phenotypic plasticity (Hutchinson 1967) or back-crossing which may be common in some lakes. For D. hyalina, $D$. galeata and their hybrids, allozyme analyses at several loci simultaneously (Table 2) can reveal genotypes which could be either a product of back-crossing or evidence of $\mathrm{F}_{2}$ hybrids, e.g. animals showing the sf genotype at $\mathrm{AO}$ and $\mathrm{ff}$ at GOT. Such genotypes are rare or absent in most lakes, although in two lakes (Kellersee, Stolper See) they have been found at a frequency of up to $9 \%$, suggesting variation in sexual fertility of hybrids or variable fitness of back-crossed or $F_{2}$ progeny. No indication for backcrossing or formation of $\mathrm{F}_{2}$ hybrids has been observed for hybrids involving $D$. cucullata, thus confirming that $D$. hyalin $a$ and $D$. galeata are more closely related to each other than to D. cucullata. The rarity of hyalina-cucullata heterozygotes suggests infrequent hybridization between these two species or low fitness of the resulting hybrids. This is in agreement with Hebert's (1985) findings for D. cephatata and $D$. carinata, who found no evidence for $F_{2}$ hybrids or backcrosses in natural populations but was able to induce sexual reproduction in a clone of hybrids thus producing $\mathrm{F}_{2}$ hybrid progeny. Thus, sexual reproduction of hybrids seems to be rare in natural populations, but may occur occasionally.

Between-lake variability of inter-specific hybridization, and within-lake succession of parent species and hybrids, can be used to generate testable hypotheses about ecological relationships between species, and differential responses to selection. For example, mating periods within a species may differ among lakes; genetic isolation between species may then be created by non-overlapping mating periods instead of mating incompatibility. Since slight differences in morphology can affect response to selection pressures (see Kerfoot 1980 for discussions of this topic), the fitness of hybrids may vary as selective regimes, e.g. predation pressure, vary among habitats. The absence or rarity of parental classes may indicate selection for hybrids in a given habitat.

The Daphnia species treated here are, as are most Daphnia species (Hebert 1978) cyclical parthenogens. The apomictic parthenogenesis of Cladocera could allow a hybrid clone to persist indefinitely; the usual costs of hybridization, meiotic incompatibility and hybrid sterility, are avoided if mating is avoided. Hybrid clones may contribute considerable genetic and phenotypic variation to a Daphnia assemblage; especially in large, permanent lakes where high population density can be maintained, large numbers of hybrid clones can be expected (Hebert 1984, 1985). Using electrophoretic markers, the amount of genetic variability contributed by hybrid clones, as well as hybrid fertility and genetic distance from parental species, can be measured. Since parental classes can now be clearly identified, formal genetic analysis may be used to examine in more detail the genetic control of phenotype.

Acknowledgements. We thank the members of the Abteilung Ökophysiologie and others who have provided assistance and samples, especially H.B. Stich, M. Kämmereit, S. Gießler, and E. Geißler. Special thanks are due Dr. J. Hrbáček, Ecological Institute, Prague, for providing taxonomic assistance, Dr. W. Lampert, Director, Abteilung Ökophysiologie for support, and Dr. J. Jacobs for critical comments on an earlier draft of the manuscript. M.A.M. gratefully acknowledges receipt of a post-doctoral fellowship from the Max-Planck-Gesellschaft.

\section{References}

Brooks JL (1957a) The Systematics of North American Daphnia. Mem Conn Acad Arts Sci 13:5-180

Brooks JL (1957b) The species problem in freshwater animals.

Table 3. Proportions of Daphnia assemblages belonging to parental and hybrid classes based on GOT genotype. The proportions are those found in plankton samples taken with oblique net tows

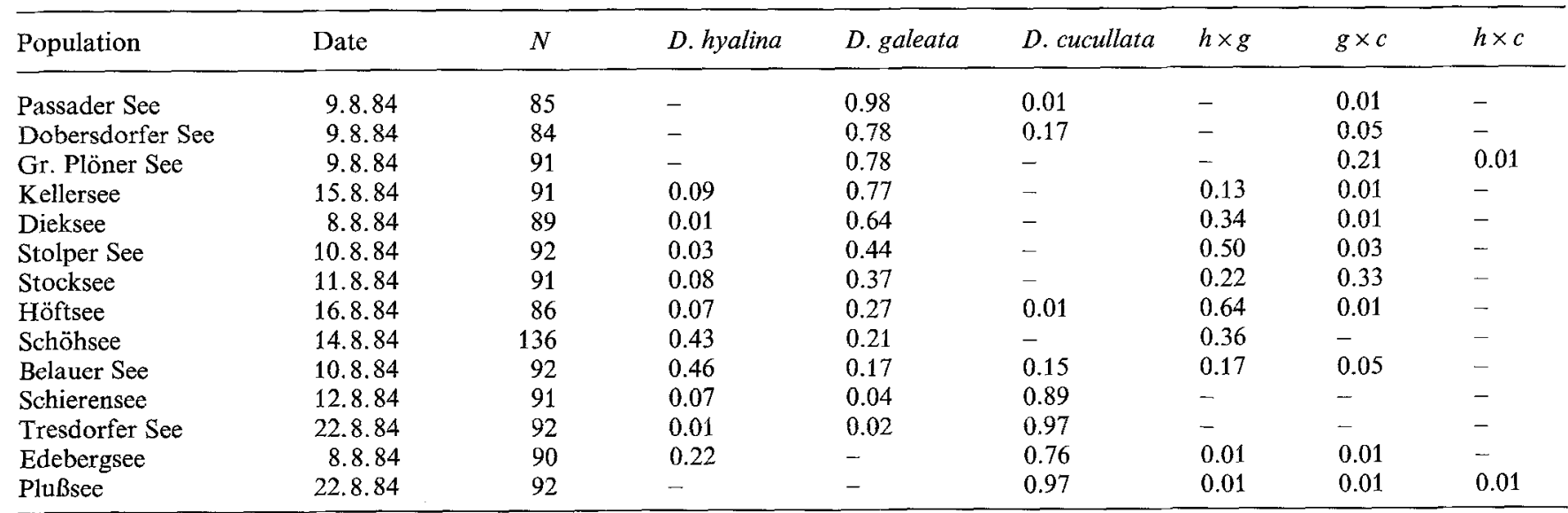


In: Mayr E (ed), The Species Problem. Am Ass Advmt Sci, Washington, D.C., pp 81-123

Einsle U (1966) Einige Beobachtungen und Hypothesen zur Taxonomie der Gattung Daphnia. Schriften des Vereins für Geschichte des Bodensees und seiner Umgebung 84:1-17

Einsle U (1983) Die Entwicklung und Männchenbildung der Daphniat-Population im Bodensee-Obersee 1956-1980. Schweiz Z Hydrol 45:321-332

Flößner J (1972) Die Tierwelt Deutschlands, 60. Teil. Gustav Fischer, Jena

Ford EB (1975) Ecological Genetics, 4th edn. Chapman and Hall, London

Hebert PDN (1978) The population biology of Daphnia (Crustacea, Daphnidae). Biol Rev 53:387-426

Hebert PDN (1984) Demographic implications of genetic variation in zooplankton populations. In: Wöhrmann $\mathrm{K}$, Loeschcke $\mathrm{V}$ (eds), Population Biology and Evolution. Springer, Berlin, pp 195-207

Hebert PDN (1985) Interspecific hybridization between cyclic parthenogens. Evolution 39:216-220
Hebert PDN, Ward RD (1972) Inheritance during parthenogenesis in Daphnia magna. Genetics 71:639-642

Hutchinson GE (1967) A Treatise on Limnology, vol. II. John Wiley and Sons, New York

Kerfoot WC (ed) (1980) Evolution and ecology of zooplankton communities. University Press of New England, New Hampshire

Lieder $U$ (1983) Introgression as a factor in the evolution of polytypical plankton cladocera. Int Revue ges Hydrobiol $68: 269-284$

Mayr E (1963) Animal species and evolution. Belknap Press of Harvard University Press, Cambridge, Massachusetts

Mort MA, Wolf HG (1985) Enzyme variability in large-lake Daphnia populations. Heredity 55:27-36

Wolf HG (1982) A comparison of different electrophoretic techniques for the detection of isozymes in single daphnids. Arch Hydrobiol 95:521-531

Received August 15, 1985 